\title{
MODELAGEM PARA AVALIAÇÃO DO GRAU DE COMPETÊNCIAS EM PLANEJAMENTO DE PARCERIAS PÚBLICO-PRIVADAS
}

\section{MODELING FOR VALUATION OF THE DEGREE OF COMPETENCE IN PLANNING OF PUBLIC-PRIVATE PARTNERSHIPS}

\author{
Edson Walmir Cazarini ${ }^{1}$; Selma Regina Martins Oliveira ${ }^{2}$; \\ ${ }^{1}$ Escola de Engenharia de São Carlos - EESC - São Carlos - Brasil \\ cazarini@sc.usp.br \\ ${ }^{2}$ Escola de Engenharia de São Carlos - EESC - São Carlos - Brasil \\ selmaregina@webmail.uft.edu.br
}

\begin{abstract}
Resumo
Este artigo tem por propósito contribuir para uma politica de planejamento em espectro de alta complexidade. Para isto concebe uma proposta de modelagem lastreada na avaliação do grau de competências no campo das parcerias público-privadas (PPPS), aplicada ao caso das concessões de rodovias no Brasil, que considera uma seqüência de procedimentos sistematizados nas seguintes fases: (i) Determinação das necessidades de informação, em duas etapas: (a) identificação dos fatores críticos de sucesso (FCS) e (b) identificação das áreas de informação (AIs); (ii) determinação das competências; e (iii) determinação do grau de avaliação de competência. A coleta de dados foi por meio de um formulário semi-estruturado, do tipo escalar, em uma matriz de julgamento, com a intervenção de especialistas. Vários instrumentos de apoio foram utilizados na elaboração da modelagem, com vistas a reduzir a subjetividade dos resultados alcançados: escalagem psicométrica - Lei dos Julgamentos Categóricos de Thurstone (LJC), MulticriteriaisCompromise Programinng, Electre III, e Promethee II; Análise Multivariada; Redes Neurais Artificiais (RNA); Redes Neurofuzzy. Os resultados produzidos mostraram-se satisfatórios, validando o procedimento proposto para as PPPS.
\end{abstract}

Palavras-Chave: parcerias público-privadas; competências; multi-modelo de referência.

\section{Introdução}

Tradicionalmente o Brasil experimenta forte processo de deterioração da infra-estrutura econômica, resultando em acentuada perda de sua eficiência e competitividade, e um dos setores mais prejudicados pela carência de recursos públicos foi o de transportes, que sofreu uma forte degradação do patrimônio instalado e perda da eficiência operacional dos vários sistemas, produzindo uma das mais importantes barreiras para o desenvolvimento nacional. E neste espectro de restrições fiscais, contrapondo-se à crescente demanda por serviços historicamente sustentados 
pelo Estado, as parcerias público-privadas (PPP) se colocam como uma das mais notáveis fontes alternativas de financiamentos freqüentemente discutidas para o desenvolvimento de projetos de infra-estruturas e a provisão de serviços à sociedade, ampliando e/ou resgatando os níveis de investimentos. Mediante esta parceria, o setor público compra serviços infra-estruturais ao invés de implantá-los diretamente, e o setor privado assume as tarefas de conceber, implantar, manter e operar as infra-estruturas e os diversos riscos daí decorrentes.

As PPPs surgiram na inglaterra em 1992, por meio das Private Finance Iniciative - PF (Iniciativa Privadas de Financiamento), com estratégia de financiamento de infra-estruturas públicas, como hospitais, escolas e o provimento de serviços públicos. A partir daí, têm sido amplamente difundidas para o resto do mundo. E a lógica subjacente às parcerias é que tanto o setor público quanto o privado apresentam características únicas que dão a cada um vantagens específicas em determinados aspectos do projeto ou do serviço a ser prestado.

Os projetos de PPPs colocam questões relevantes e de grande complexidade, num contexto de incerteza e risco, e as características dos projetos diferem muito, sendo objeto de análise igualmente diferenciada. A experiência internacional tem mostrado claramente que as principais causas de fracassos dessa modalidade de projetos podem ter origem em diferentes elos da cadeia, os quais talvez fossem considerados insuspeitados, o que levou à descontinuidade dos projetos. Tomando-se os pressupostos do modelo internacional de PPPs, o Brasil encontra-se em uma desvantagem temporária e financeira: a experiência é ainda pouca, as ferramentas analíticas e de decisão ainda têm pouca divulgação, a legislação se mostra inadequada e o capital intelectual despreparado.

O desenrolar de um projeto de parcerias público-privadas (PPPs) se apresenta como uma cadeia complexa de eventos e decisões, a qual pode se romper em qualquer elo mais fraco: alguns projetos se perderam em função de previsões irrealistas, ou erro no dimensionamento de recursos. Seja como for, cada projeto se constrói a partir de uma história particular, pelo que há limites para se impor procedimentos padronizados em detalhe. Via de regra, a gerência de um projeto de PPPs desdobra-se em um conjunto concatenado de subprocessos, também nada simples. E na medida em que o projeto de PPPs há de satisfazer perspectivas de atores, sua elaboração tem de contemplar critérios por vezes conflituosos.

As características dos projetos de PPPs diferem muito, sendo objeto de análise igualmente diferenciada. Além disso, a literatura ainda diverge no tocante a concepção de um business case. A boa prática recomenda a seguinte estrutura em duas fases (Bennett et. al., 1999; Padecco, 1999; Partnerships Victoria, 1999; Ingerson, 2000; Office of Government Commerce, 2001; Queensland Governament, 2001; Province Nova Scotia, 2003): (i) identificação das necessidades de investimentos; (ii) institucionalização e formação da equipes de projeto; (iii) consolidação dos 
objetivos, resultados e metas de desempenho do projeto; (iv) esboço do projeto de referência; (v) mapeamento das opções institucionais; (vi) estudo dos custos, receitas, fluxos de caixa; (vii) estudo dos impactos sociais, políticos e ambientais; (viii) análise, alocação e gestão de riscos; (ix) análise da viabilidade básica e indicações para a estrutura de financiamento; (xi) $1^{\circ}$ Relatório e rodada de comunicação e recomendações e aprovação. Na segunda fase, listam-se as seguintes etapas: refinamento do projeto, das opções institucionais e estudos de custos, impactos de risco, de viabilidade e de financiamento; e por fim, o relatório final. De todos esses elementos resulta a atratividade de um projeto de PPPs, sobretudo o seu retorno e estabilidade, o que requer domínio técnico de diversos processos tecnológicos, contratuais (jurídicos), financeiros e políticos.

No Brasil, os projetos de PPPs ainda é uma tarefa científica mal começada, embora se possa enumerar uma quantidade de títulos já disponíveis sobre o assunto, poucas obras se prestam para a construção sistemática da experiência brasileira no setor. Os métodos e técnicas se encontram em situação de desvantagem quando se compara às experiências internacionais: é carente em aportes materiais, tecnológicos e, sobretudo em recursos humanos. O conhecimento é insuficiente e o capital intelectual é despreparado, o que torna insustentável viabilizar projetos tão relevantes. Seja como for, os modelos seguem, de alguma forma, uma lógica racional, embora com muitos acidentes de percurso e erros no detalhe.

Neste espectro, é essencial o aumento da capacidade institucional do Estado brasileiro, em suas funções de formulação, avaliação e implementação de projetos de PPPs, pois a eficiência da gerência de tais projetos deve estar balizada em competências que permitam uma avaliação correta sobre as decisões a serem tomadas. Paralelamente a isto, há de se recorrer a formação dos recursos humanos para superar esses desafios. E a capacitação é um processo sistemático e contínuo de avaliação das necessidades futuras de recursos humanos, o que requer pessoas com competências adequadas para desempenhar as tarefas corretas no local e momento oportuno.

Este trabalho tem por objetivo desenvolver uma modelagem de avaliação do grau de competências para planejamento de projetos de parcerias público-privadas (PPPs), com aplicação ao caso das Concessões de Rodovias no Brasil. A opção pelas Concessões se justifica, por se valer das mesmas regras das PPPs, e não contemplar projetos revestido sob esta modalidade no Brasil. Foram utilizados como métodos de apoio: o método de escalagem psicométrica, Lei dos Julgamentos Categóricos (LJC), desenvolvido por Thurstone em 1927; as Redes Neurais Artificiais (RNA); os métodos multicriteriais: Electre III, Compromise Programinng; e as redes Neurofuzzy. A aplicação destes métodos tem por objetivo reduzir o grau de incerteza produzidos pela subjetividade nos resultados alcançados. Espera-se que o conhecimento prévio desses elementos possibilite traçar uma forma aproximada daquilo que se chama de desejável em termos de competências. 


\section{O Método: passos e aplicação}

A seguir estão sistematizadas as fases e etapas do modelo e, paralelamente evidenciam-se os resultados. O universo da pesquisa foi constituído por especialistas, selecionados por critério técnico-científico, com conhecimento sobre o objeto de estudo. Os dados foram extraídos à luz da literatura e submetidos ao julgamento de especialistas com conhecimento em gestão de projetos de PPPs/Concessões, como: Agência Nacional de Transportes Terrestres - ANTT; Agência Reguladora de Serviços Públicos de Transportes do Estado de São Paulo - ARTESP; Departamento Nacional de Estradas - DENIT; Banco Interamericano de Desenvolvimento - BID; Banco Nacional de Desenvolvimento Social - BNDES; Concessionária CONCEPA; Concessionária ECONORTE; Concessionária ECOSUL; Tribunal de Contas da União - TCU; e especialistas de Empresas de Recursos Humanos, com conhecimento em gestão de pessoas. Os métodos e técnicas de apoio foram: brainstorming, preferência declarada, Likert e Lei dos Julgamentos Categóricos de Thurstone, redes neurais e neurofuzzy, entre outros. Detalham-se as fases e etapas da modelagem.

Fase 1: Tomada de Decisão e Solução de Problemas: Como fase preparatória deste modelo de referência, a estruturação do problema de pesquisa foi elaborada à luz da Metodologia dos Sistemas Flexíveis - Soft Systems Methodology (SSM).

Fase 2: Modelagem das Necessidades de Informação: Esta fase está subdividida em: modelagem dos Fatores Críticos de Sucesso (FCS) e modelagem das áreas de informação.

Etapa 1: Modelagem dos FCS: Os FCS foram identificados inicialmente a partir de uma satisfatória revisão da literatura especializada e combinada com diversos métodos: (i) análise ambiental; (ii) análise estrutural da indústria; (iii) consulta a especialistas (negócio); e (iv) fatores temporais / intuitivos. A intervenção de especialistas foi determinante no julgamento dos FCS.

Figura 1: Classificação dos FCS

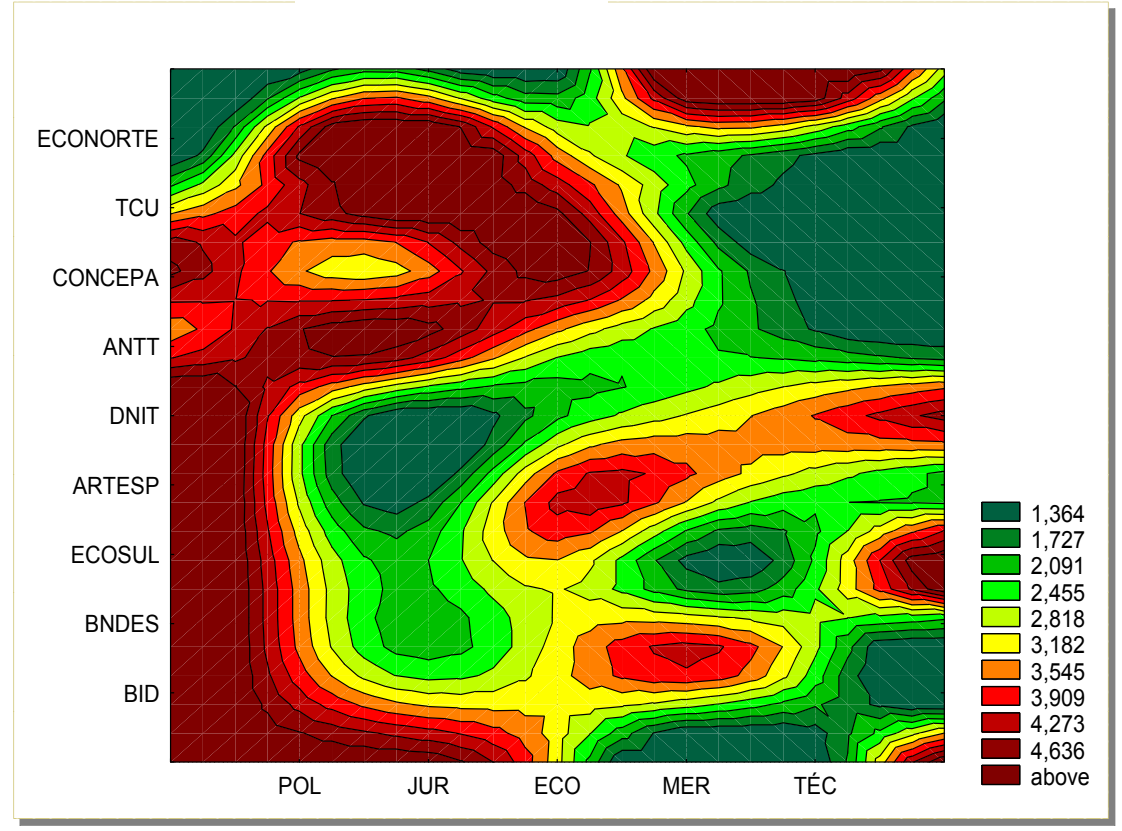


Uma vez identificados os FCS, esses foram agrupados utilizando a análise de cluster, atendendo ao princípio da arborescência, que permite o desdobramento dos FCS em diferentes processos ou áreas envolvidas, e observando-se sempre as relações de pertinência. Logo após esse procedimento, aplicou-se o método LJC para avaliar os FCS agrupados, escalonando-os. Os resultados evidenciaram a seguinte classificação: (1º) Político/Jurídico; (2º Técnico; $\left(3^{\circ}\right)$ Econômico e Financeiro e ( $\left.4^{\circ}\right)$ Mercadológico (Figura 1).

O Fator Político é o mais importante na visão dos especialistas. Isto deve-se ao fato da relevância das políticas públicas para o desenho das PPPs. A determinação política na provisão dos serviços são vistos como pressupostos essenciais na viabilidade desse mecanismo de financiamento. A partir de um arcabouço institucional político estável decorre o sucesso ou fracasso desta categoria de projetos. À luz das históricas experiências políticas no contexto internacional e brasileiro explica-se a preferência pelo Fator Político. Sem dúvida, a instabilidade política trouxe consigo a descontinuidade de grandes e bons projetos. Na maioria das vezes, a instabilidade política despontou em crises sistêmicas e de grandes proporções, colocando as políticas públicas, os investimentos, os projetos, programas e diretrizes do Estado em segundo plano. Nesse panorama, com a definição do fator político e seus componentes, torna-se possível conhecer informações a respeito das macro diretrizes definidas por meio das políticas públicas; as decisões estratégicas dos governantes, dos órgãos reguladores e suas entidades competentes para regulamentar, legislar e contratar, entre outras.

Etapa 2: Modelagem das Áreas de Informação - AIs: Uma vez selecionados os FCSs, foram definidas as Áreas de Informação (AIs) em função da respectiva afinidade com os diferentes componentes dos FCS. Paralelamente desenvolveu-se uma vasta revisão da literatura especializada. Por AIs entende-se o local que recebe informações críticas para a construção e gerência dos projetos de PPPs. A confirmação das AIs foi por meio de entrevistas / consultas aos especialistas. Para avaliar as AIs utilizou-se o método LJC. Eis os resultados produzidos: (1 $\left.1^{\mathrm{a}}\right)$ Política; $\left(2^{\mathrm{a}}\right)$ Econômica e Financeira; $\left(3^{\mathrm{a}}\right)$ Técnica; e $\left(4^{\mathrm{a}}\right)$ Mercadológica.

Etapa 3: Desempenho das AIs em Relação aos FCS: Com a determinação das AIs foi possível identificar sobre qual delas é necessário enfatizar a coleta de informação. Para isto, determinou-se o desempenho global dessas AIs utilizando-se os métodos multicriteriais: Compromise Programming, Promethee II e Electre III. O que permitiu identificar a AI mais importante para assegurar os FCS. Os resultados evidenciam a seguinte classificação, por importância: (1 $\left.{ }^{\mathrm{a}}\right)$ Política; (2a) Mercadológica; (2a) Técnica; e ( $3^{\mathrm{a}}$ ) Econômico-Financeira. A AI Governamental Políticas Públicas (AGPP) como a mais importante para assegurar os FCS. Esta Área responde pelas atividades 
relacionadas com o planejamento, execução e avaliação das questões políticas dos projetos de PPPs/Concessões de rodovias. Sendo assim, a partir dessas atividades, esta AI requer coletar, analisar e processar as informações que reforçam o conjunto de atividades que conformam esta área, como por exemplo: (i) política e ambiente institucional das PPPs / concessões; (ii) negociações na montagem dos projetos e seleção dos concessionários; e (iii) ambiente jurídico geral, entre outros. Esses resultados permitem aos gestores concentrar melhor seus esforços e recursos na gestão da AI que apresenta o melhor desempenho.

Fase 3: Modelagem das Competências: Reunindo as dimensões propostas na construção do modelo de avaliação de competências: conhecimentos, habilidades e atitudes, esta fase foi estruturada conforme as seguintes etapas: Etapa 1: definição do conceito; Etapa 2: identificação e captura; e Etapa 3: avaliação. As três dimensões foram identificadas a partir da literatura consultada e confirmadas junto a especialistas. Passa-se a sistematizar essas etapas.

\section{Conhecimento}

Etapa 1: Definição do Conceito de Conhecimento: Passa-se a sintetizar os principais conceitos e elementos extraídos para os fins que ensejam este trabalho. Procedeu-se a seleção de fontes segundo sua relevância. A definição que orientou esta aplicação seguiu a proposta de Nonaka (1994); Nonaka e Takeuchi (1995); Laudon e Laudon (1998); Moresi (2001); O’Brien (2001); Laudon e Laudon (2001); Stair e Reynolds (2002): dados (processamento) informação (elaboração) conhecimento (síntese) inteligência, respectivamente. Dado - conjunto discreto e objetivo de fatos sobre um determinado evento ou objetos. É portando, a parcela quantificável e objetiva do estoque de informação e conhecimento de uma empresa, e está armazenado em bancos de dados ou documentos da empresa. Informação: mensagem contendo um emissor e um receptor e cujo significado envolve uma nova interpretação de algo, baseado em um conjunto de dados. Conhecimento: é uma mistura fluida de experiências, valores, teorias, informação de contexto e intuição, formando um framework (um painel) na mente de uma pessoa que a habilita a interpretar, avaliar e tomar decisões acerca de casos, experiências e/ou informações. O termo conhecimento é definido, portanto, como algo que não pode ser totalmente estruturado (não-papável), impossível de ser totalmente capturado e ter sua lógica dissecada (desestruturada), e que, por tudo isso, está presente somente dentro das pessoas. Mas ainda, o conhecimento só se manifesta quando é utilizado. Stair e Reynolds (2002) ressaltam que “o conhecimento representa a percepção e a compreensão de um conjunto de informações e de como estas informações podem ser úteis para uma tarefa específica". "O conhecimento pode ser dito como sendo aquilo que cada indivíduo constrói como produto do processamento, da inter-relação entre interpretar e compreender a 
informação" (LITO; FORMIGA, 2008). Deste conjunto, origina-se uma característica importante desta definição de conhecimento: sua orientação para ação. O conhecimento só se materializa quando empregado e, quanto maior o conhecimento de uma pessoa, mais rica e frutífera será a sua apreciação e análise dos dados e informações disponíveis. Conseqüentemente, maior a qualidade das decisões tomadas durante sua rotina diária nas empresas (DAVENPORT; PRUSAK, 1998).

Conhecimento seguiu ainda a lógica de Davenport e Prusak (1998), é a informação mais valiosa porque precisamente alguém deu a ela um contexto, um significado, uma interpretação, alguém refletiu sobre o conhecimento, acrescentou a ele sua própria sabedoria, considerou suas implicações mais amplas. Davenport (2001), Moresi (2001); Bukowitz e Williams (2002); Probst et. al. (2002) salientam que conhecimento é a informação elaborada, refinada, avaliada sobre a sua confiabilidade, sua relevância e sua importância. E é por meio da síntese da informação, que há a conversão da informação em conhecimento. Após esta síntese, reúne-se a informação em blocos de tal forma que posteriormente possam ser utilizados por especialistas que filtram-na e padronizam-na para aplicá-la a uma situação específica. Uma vez exposta essa corrente de elementos definidores de Conhecimento, adotam-se as Informações de Contexto - (IC) e as Bases Teóricas e conceitos (BTC) como definição de conhecimento na presente aplicação.

Por informações de contexto entendem-se as informações analisadas e avaliadas a partir das áreas de informação levantadas na Fase 2, onde tais informações foram identificadas e capturadas (ambiente interno e externo, a partir da literatura especializada e por meio de entrevistas (formulário semi-estruturado) junto a especialistas, conforme a necessidade de alimentar o desenvolvimento das atividades e ações ali articuladas, para viabilizar projetos. São informações elementares para a eficiência e sucesso desta categoria de projetos. Por Bases Teóricas e Conceitos, entendem-se as habilidades conceituais. Por habilidades conceituais entendem-se as habilidades que envolvem a visão da organização ou da unidade organizacional como um todo, a facilidade em trabalhar com idéias e conceitos, teorias e abstrações. As habilidades conceituais estão relacionadas com o pensamento, o raciocínio, o diagnóstico das situações e a formulação de alternativas de solução dos problemas. Representam as capacidades cognitivas mais sofisticadas do gestor e que lhe permite planejar o futuro, interpretar a missão, desenvolver a visão e perceber oportunidades. Na seqüência aborda-se a forma como esse conhecimento foi identificado e capturado.

Etapa 2: Identificação e Captura do Conhecimento: A identificação do conhecimento é a primeira etapa do processo da Gestão do Conhecimento. Foram consideradas as duas definiç̧ões para esta aplicação: informações de contexto e bases teóricas e conceitos. As informações de contexto serão identificadas, capturadas e mapeadas ainda na feitura da Fase 2, por meio de entrevista e formulário semi-estruturado aplicado e confirmado junto aos especialistas com conhecimento sobre o objeto de estudo/aplicação, por área de informação (do objeto de estudo/aplicação). Sendo assim, uma vez 
identificadas e capturadas, foram nesta fase, elaboradas, analisadas e avaliadas para se tornarem compreensíveis aos tomadores de decisão (usuários da informação) na montagem e gestão dos projetos de PPPs, objeto de aplicação, seguindo a analogia e hierarquia de dado, informação e conhecimento. Em seguida, essas informações foram revisadas e organizadas e validadas por especialistas envolvidos direta ou indiretamente com o objeto de aplicação (no caso, os projetos de PPPs). O procedimento para identificar as informações partiu da determinação das teorias e conceitos relevantes que necessários para viabilizar a consecução / operacionalização da montagem e gerência dos projetos de PPPs. Prossegue-se então rumo à captura deste conhecimento já identificado (Fase 2). “Após analisar e validar as informações, estas passaram ao estágio de conhecimento, ou seja, a informação compreendida. É por meio do conhecimento que aqueles que assessoram as decisões buscam uma compreensão mais efetiva da situação problema” (MORESI, 2001). E essas informações analisadas e avaliadas produzem o conhecimento, que é a informação elaborada, refinada, avaliada sobre a sua confiabilidade, sua relevância e sua importância. O conhecimento é obtido pela interpretação e integração de vários dados e informações para iniciar a construção de um quadro de situação (Moresi, 2001; Bukowitz e Williams, 2002; Probst et. al., 2002), e sugerem os seguintes métodos como instrumentos de análises das informações: Análise SWOT - (Strengths), Fraquezas (Weaknesses), Oportunidades (Opportunities) e Ameaças (Threats); Sinergias; Benchmarking; Perfis Gerenciais; Monitoramento Tecnológico, Análise Morfológica, Análise Competitiva Dinâmica de D`Aveni; Cadeia de Valores de Porter; e Técnica de Cenários. Neste trabalho foi usada a Análise SWOT. A aquisição do conhecimento envolveu a extração, interpretação e representação do conhecimento de um dado domínio e foi considerado como sendo o estágio mais difícil e precário. O processo de captura representou a aquisição de conhecimentos e experiências necessárias para criar e manter as competências essenciais e áreas de conhecimento selecionadas e mapeadas. Capturar o conhecimento dos especialistas implica, segundo Buchanan (1999), em obter informação dos especialistas e/ou fontes de documentação, classificar essa informação de forma declarativa ou procedural, codificar essa informação num formato utilizado pelo sistema e validar a consistência do conhecimento codificado com o conhecimento existente no sistema. Assim sendo, o procedimento adotado abordou a forma como foi realizada a conversão da informação ao estágio de conhecimento, que é a informação compreendida e útil na tomada de decisão em projetos de PPPs. Num primeiro momento, as informações foram coletadas. Em seguida estabeleceram-se a combinação e a interiorização através do conhecimento, de explícito para explícito, pois as informações já estavam mapeadas, formalizadas, para ser melhor compreendida e sintetizada de forma a ser apresentada conforme todos a entendessem mais fácil e rápido quando possível (a informação deve ser útil na tomada de decisão, para isso, deve ser compreendida). A simples atividade de comparar e contrastar informações é uma forma de análise. Eis alguns 
procedimentos para capturar o conhecimento: (Thiel, 2002): Entrevista, Mapeamento da Informação, Mapeamento do conhecimento e Conversação. Sendo assim, para converter a informação ao estágio de conhecimento (transformação), adotou-se o seguinte procedimento para a conversão de informações em conhecimentos: (i) estabeleceu-se a comparação de como as informações relativas a uma determinada situação pode ser comparada a outras situações conhecidas; em segundo lugar, (ii) analisou-se e avaliou-se as implicações que as informações trazem para as tomadas de decisões; em terceiro lugar, (iii) estabeleceu-se a relação entre um novo conhecimento com o conhecimento acumulado; em quarto lugar, (iv) certificou-se o que os tomadores de decisão esperavam da informação. Adotou-se ainda os seguintes critérios: (i) determinação da relevância e valor do conhecimento ou da informação; (ii) determinação do grau de confiabilidade desse conhecimento; (iii) identificação e consolidação do conhecimento útil e descarte de conhecimento redundante; (iv) contratação; (v) redução do grau de incerteza do conhecimento não comprovado; (vi) identificação e proposição de soluções de problemas relacionados a em primeiro lugar, (i) estabeleceu-se a comparação de como as informações relativas a uma determinada situação pudessem ser comparadas a outras situações conhecidas; em segundo lugar, (ii) analisaram-se e avaliaram-se as implicações que as informações proporcionassem para as tomadas de decisões; em terceiro lugar, (iii) estabeleceu-se a relação entre um novo conhecimento com o conhecimento acumulado; em quarto lugar, (iv) certificou-se o que os tomadores de decisão esperavam da informação conhecimentos conflitantes; e por fim, (vii) o estabelecimento de visões múltiplas para casos de conhecimentos conflitantes não selecionados.

A conversão da informação em conhecimento contou com o apoio dos mapas de informação, elaborados na fase anterior por área, por meio de análise e avaliação da informação. É bom ressaltar que as informações consideradas foram tanto as de origem externas como as internas. As informações de origens externas têm por finalidade principal detectar, com antecedência, oportunidades ao projeto em um futuro mais remoto (CÉLIS, 2000). As informações internas são importantes para estabelecer as estratégias, mas elas devem ser mais abrangentes do que a utilizada para a gestão operacional, pois além de permitir a avaliação do desempenho, ela tem a importante finalidade de identificar forças e fraquezas (CÉLIS, 2000). Sendo assim, a título demonstrativo, as ICs da categoria Governamental Políticas Públicas identificadas são: Política e Ambiente Institucional das PPPs e Concessões, Negociações na Montagem dos Projetos e Seleção dos Concessionários e Ambiente Jurídico Geral: organização institucional, planejamento estratégico do desenvolvimento das infra-estruturas e adaptação na legislação e adequação na estrutura do setor público significam. As ICs foram identificadas à luz da literatura e em seguida confirmadas junto aos especializas (ambiente externo). Uma vez estabelecida a conversão das informações em conhecimentos (informações de contexto), na etapa seguinte determinou-se as bases teóricas e 
conceitos. As BTC foram identificadas à luz da literatura especializada e consulta junto a especialistas.

$\mathrm{Na}$ sequência, abordam-se os procedimentos para a captura das bases teóricas e conceitos. Esse procedimento (I) iniciou-se tomando por base as áreas de informação, uma a uma, em que serão então, identificados os conceitos e teorias que fundamentam o desempenho das ações (articulações) desenvolvidas nas referidas áreas de informação que permitem assegurar a viabilidade dos projetos. Ou seja, quais os conceitos e teorias são necessários conhecer para assegurar o desenvolvimento das atividades e ações para que os projetos sejam bem sucedidos, naquela área (identificada na Fase 2). Em seguida, (ii) prosseguiu-se então em analisar, por meio de pesquisas realizadas junto às instituições públicas e privadas (empresas, órgãos públicos, entre outros) sobre o mercado de profissionais demandados por essas instituições, suas competências, no caso conhecimentos, observando-se as exigências em áreas similares às contempladas neste trabalho (estudo comparado).

Do lado da oferta, buscou-se pesquisar o nível de conhecimento demandado pelas empresas e outras organizações, nas referidas áreas, aliado a oferta no que tange à capacitação (forma, meios) dos profissionais (ou seja, que tipo de profissional está sendo demandado pelas instituições? Que tipo de profissional é ofertado para atender a essa demanda?). As ICs e as BTCs foram identificadas: (i) à luz da literatura especializada e documentos; (ii) das experiências internacionais de casos bem sucedidos e de fracasso; (iii) análise das experiências de concessões de rodovias no Brasil; (iv) consulta a especialistas; (v) análise ambiental em órgãos públicos cujos profissionais desempenham atividades similares na gestão de projetos (conhecimento técnico demandado, entre outros). Os resultados foram produzidos segundo o julgamento dos especialistas das seguintes instituições: ANTT; ARTESP; BID; BNDES; CONCEPA, DENIT, ECONORTE, ECOSUL, e TCU, utilizando o método LJC. Para melhor compreensão, os objetos de conhecimentos foram organizados em clusters, e apresentados em mapas mentais com objetivo de capturar as visões dos especialistas e evidenciar a consistência na construção das idéias dos decisores na montagem e gestão de projetos de PPPs. Os mapas se colocam como uma das mais notáveis estratégias metodológicas utilizadas neste trabalho voltadas para estruturar o conhecimento explícito dos decisores no gerenciamento de projetos de PPPs, nos seus diferentes segmentos, explorando questões conceituais, teóricas, metodológicas e técnicas, que cercam o uso dos mapas cognitivos na investigação de importantes domínios, especialmente desenhados no campo da formulação de estratégias de PPPs / concessões. Os mapas passam por um processo de desenvolvimento constante e sempre estão atualizados à luz das experiências de aprendizagem dos especialistas. A título ilustrativo, a seguir estão evidenciados os resultados das categorias Governamental Políticas Públicas e Econômica e Financeira. 
Categoria: Governamental Políticas Públicas: Eis a intensidade nas preferências dos especialistas pelas bases teóricas e conceitos necessários na montagem e gerência dos projetos de PPPs/Concessões de rodovias no Brasil, avaliados segundo o método LJC (Figura 2).

Figura 2: Bases teóricas e conceitos conforme as preferências dos decisores - Categoria Governamental Políticas Públicas

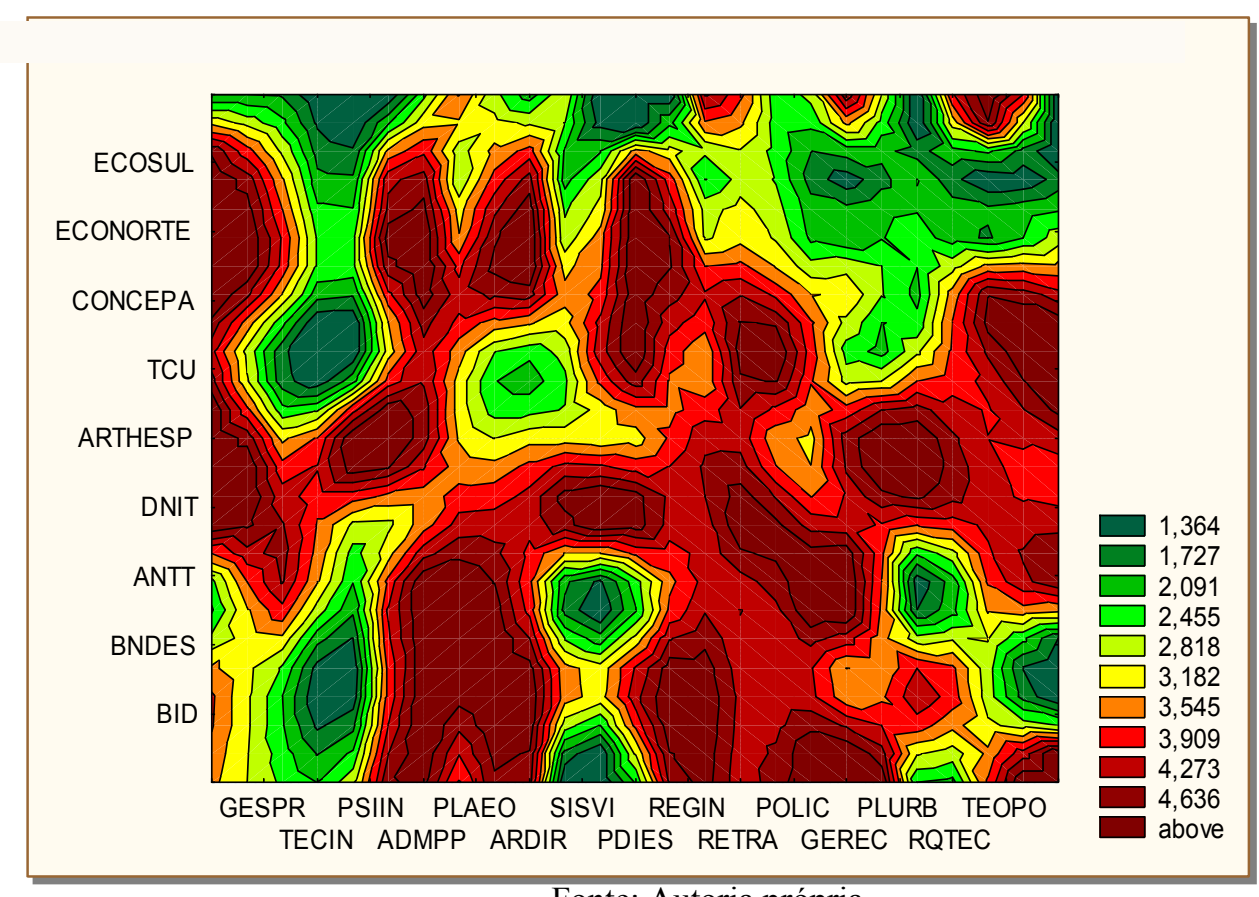

Fonte: Autoria própria

Reconhecido o interesse estratégico das PPPs para o desenvolvimento do país, a legislação haverá de se adequar às práticas internacionais. Pelo menos na exata medida em que se demonstre como indispensável aos interesses nacionais. Eis alguns aspectos fundamentais que deveriam ser abrangidos por uma legislação própria de PPPs: (a) a escolha do contratado; e (b) a execução e gestão do contrato. A legislação de licitação e concessão no Brasil, adotada em uma era conturbada por diversos escândalos, visa antes de mais nada, impor rigor e transparência nas relações públicoprivadas.

Sem dúvida, a Administração Pública tem à sua frente desafios, que visa antes de tudo, reafirmar a necessidade de adotar uma política ativa de planejamento estratégico e um esforço sistemático em compor um arranjo para um novo relacionamento ente o setor público e privado. Neste novo relacionamento a Administração Pública há de firmar a liderança do processo e a primazia do interesse público. A política regulatória e a reforma do Estado, especialmente o papel das agências reguladoras, seriam igualmente tangidas. Trata-se de consolidar, de início, os princípios jurídicos básicos da função reguladora e do papel da Administração Pública e dos organismos reguladores no setor de transporte, reforçando-se o ato de delegação de serviços públicos enquanto admissão da iniciativa privada sob a condição de se alcançarem desempenhos 
finais e se assumirem obrigações. Neste âmbito, a regulação irá condicionar o processo competitivo, que seria o regime comum, inclusive os setores de utilidade pública, às restrições inerentes ao regime de monopólio natural e dos serviços públicos, mas resguardando a competição.

Clarividente que as PPPs só podem ter a sua aplicação ampliada se forem objeto de uma política consistente, que permeie os diversos estratos administrativos e Poderes dos níveis federal, estadual e municipal, o que requer uma coordenação nacional que permitirá uma sinergia entre os projetos de investimentos em infra-estruturas, sinergia esta buscada há anos pelo planejamento estratégico brasileiro. Igualmente, o esforço de criar um capital intelectual brasileiro sobre o tema exige coordenação, reconhecida por diversos países - à frente deles, o Reino Unido, Estados Unidos e Austrália.

Categoria: Econômica e Financeira: Evidenciam-se os resultados produzidos pela categoria Econômica e Financeira. A modelagem de negócio (MODNE), gestão de riscos (GRIS) e a engenharia financeira (EFPF) são os objetos de conhecimento mais importantes no julgamento dos especialistas na categoria econômica e financeira.

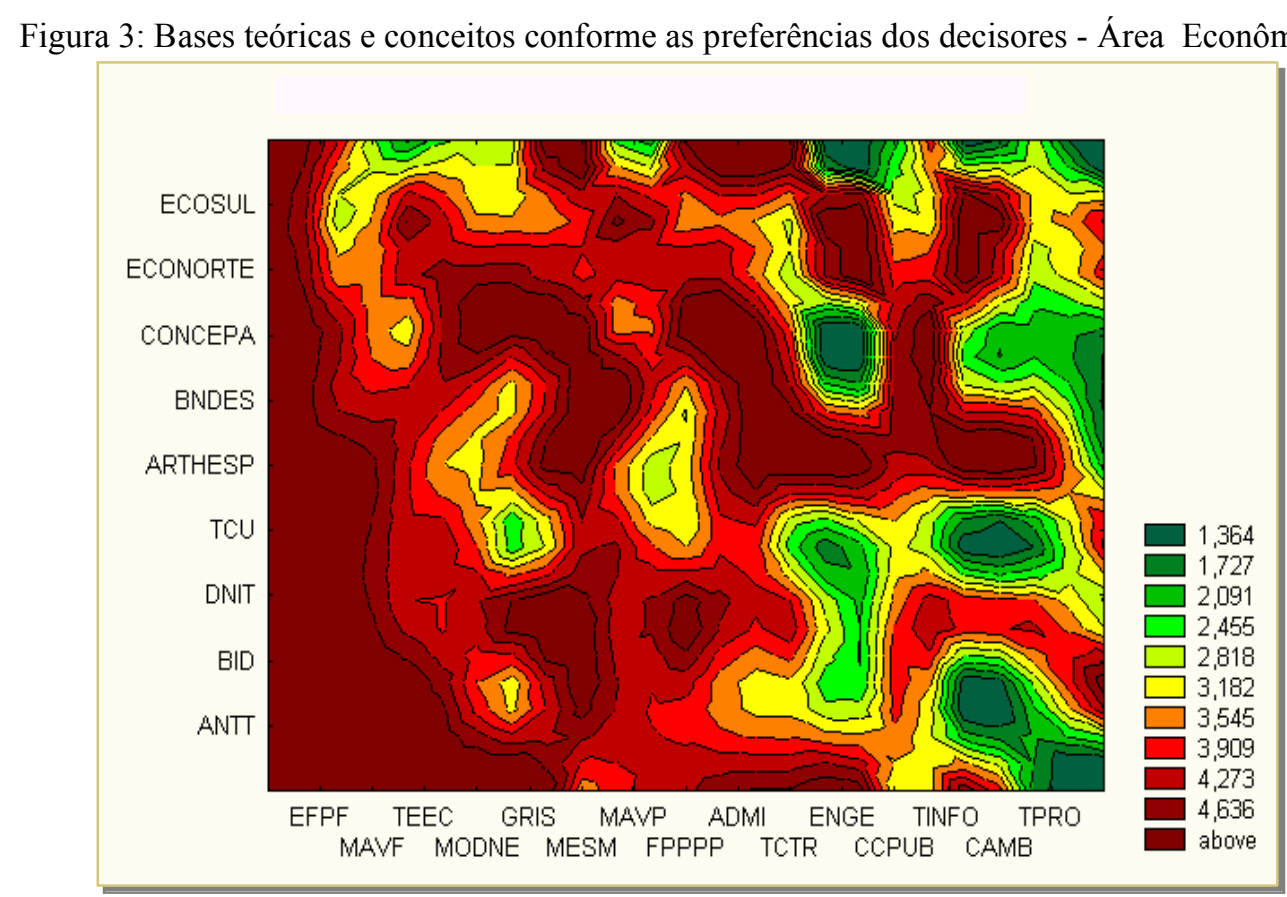

Fonte: Autoria própria

Entra-se num campo central para a viabilidade da parceria. Em se tratando de investimento privado, sem dúvida o resultado financeiro e a respectiva estabilidade são critérios fundamentais na adesão de parceiros comerciais. Vários pontos têm de ser satisfeitos nesse âmbito, que se deixem sistematizar em: (i) qualidade das análises e previsões econômicas e financeiras; (ii) envolvimento efetivo do setor financeiro e acesso a fontes de financiamento; (iii) papel dos fundos fiscais; (iv) gestão e repartição de riscos; (v) política geral de tarifação de infra-estruturas; (vi) aceitabilidade de 
preços; (vii) estruturas de custos; (viii) engenharia financeira; entre outros. A Engenharia Financeira (EFPF) é uma das fases mais sensíveis do projeto e requer procedimentos adequados. O desenrolar de uma Engenharia Financeira atravessa todas as etapas da parceria, dos estudos aprofundados das demonstrações financeiras, a questão dos riscos, até a montagem final da Engenharia Financeira. Hão de ser preliminarmente mapeados e levantados os mais diversos custos de diferentes categorias (construção, operacional, administrativos, financeiro etc), as receitas operacionais diretas e indiretas e os respeitos cronogramas de entradas e saídas. O fluxo de caixa resultante tem que ser submetido a uma análise de sensibilidade, e os fatores de riscos precisam ser sistematizados. Pelo project finance é possível que se elimine total ou parcialmente o risco, à medida em que esse instrumento gera um compartilhamento de riscos. Evidenciam-se os fluxos e critérios para o desenho e desempenho financeiro do projeto, o retorno, a taxa de cobertura, a vida útil do projeto, o prazo de concessão e cronograma de fornecimentos e construções, custo do capital e custo da estrutura, necessidades de capital e índice máximo de endividamento dos concessionários. Isto permite contribuir para: (b) a manutenção do equilíbrio econômico-financeiro; (c) endividamento equilibrado; e (d) credibilidade do projeto. No conjunto, ao comparar as IC e BTC, a categoria Econômica e Financeira e a Gestão Governamental Políticas Públicas se apresentam como as categorias mais importantes. As manifestações das preferências dos decisores acontecem em instantes diversos, e os valores de escala variam em função da própria dinâmica mental dos decisores. À luz da escala apresentada $(-6 ; 8)$, são priorizados os objetos de conhecimentos de todas as categorias de conhecimentos fundamentais na montagem e gestão de PPPs. É portanto, uma lista muito limitada que reflete a cultura anglo-saxônica de parcerias, em que as questões do relacionamento entre atores sociais, a construção dos processos político e de participação ainda não aparecem como temas-chave. 
Figura 4: Variação da dispersão das preferências dos decisores - BTC e IC

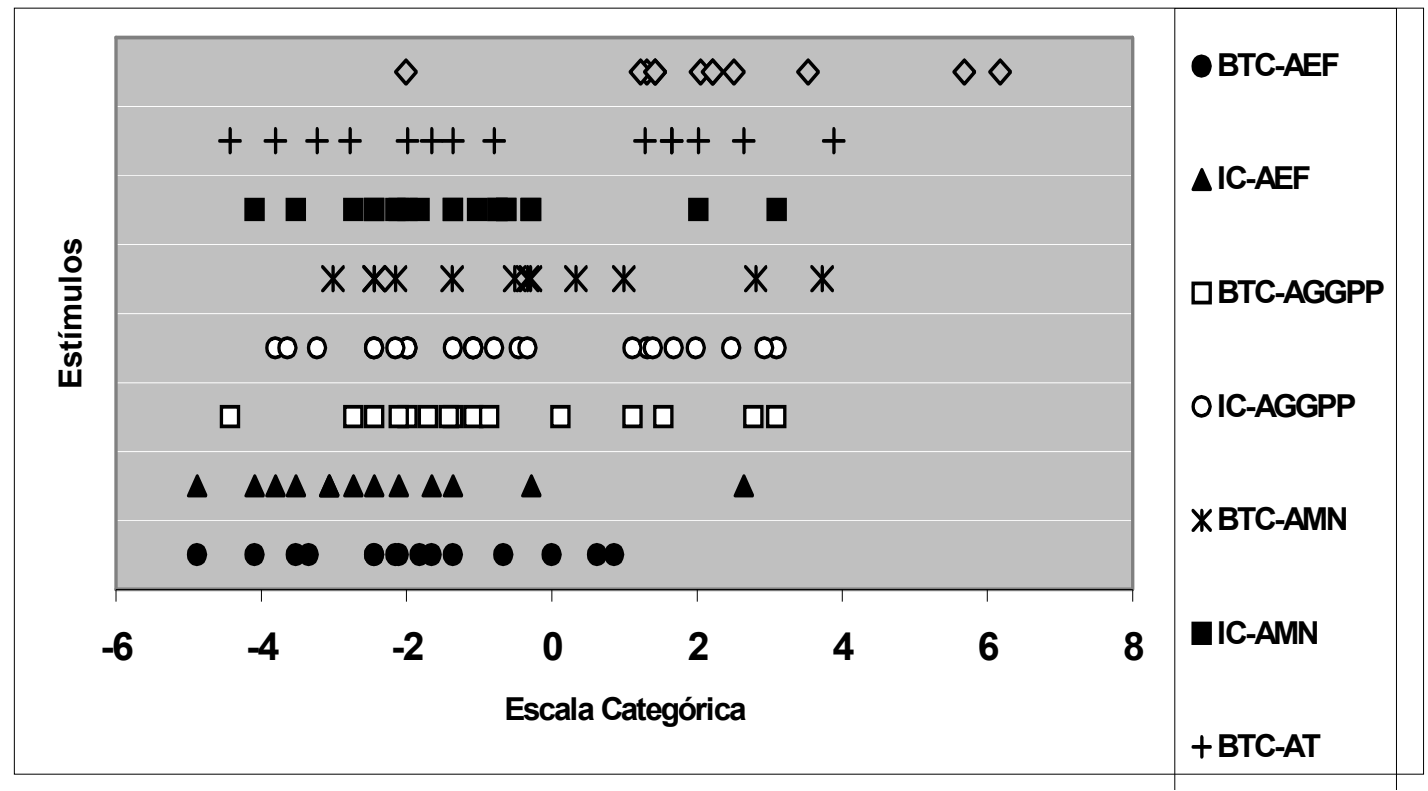

Fonte: Autoria própria

Claro está também, que a listagem de prioridades é dinâmica, depende essa, pois, do estado inicial da capacitação, das características concretas dos projetos e da política de parcerias e dos problemas cognitivos que vão surgindo ao longo da prática, sempre colocando em pauta novos conteúdos.

Ao avaliar os objetos de conhecimento utilizando as RNA, os resultados que mais se aproximou da classificação obtida pelo método LJC foi a RNA 1.

Figura 5: Avaliação dos Objetos de Conhecimentos - LJC e RNA

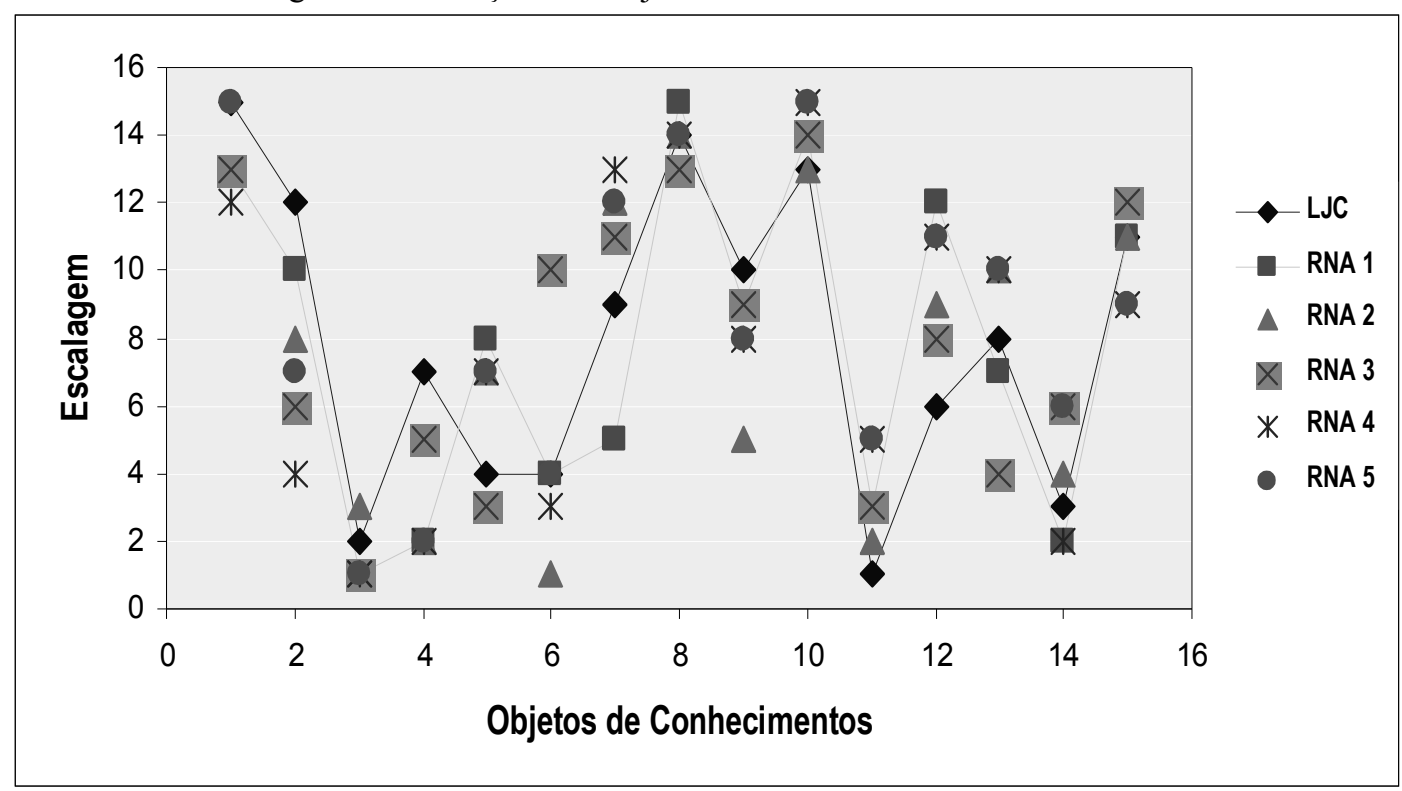

Fonte: Autoria própria

Isto confirma a consistência dos resultados, e também a confiabilidade dos referidos instrumentos em procedimentos de classificação, avaliação, priorização, escalagem, de variáveis 
qualitativas. Assim, seguindo a analogia de Moresi (2001), Bukowitz e Williams (2002), o modelo proposto diferencia-se de outros métodos de apoio à decisão por extrair o conhecimento tácito e convertê-lo em conhecimento explícito, tornando o espectro de decisão mais inteligente, disponibilizando conhecimentos sobre o desenvolvimento e gerência dessa categoria de projetos.

Habilidades: A dimensão que orienta o conceito de habilidades nesta aplicação é o de saber- fazer, como uma dimensão da competência. Os dados foram extraídos da literatura e submetidos ao julgamento de especialistas para confirmação dos resultados. Foram selecionados vários títulos sobre habilidades em PPPs, especialmente (mas não exclusivamente) daqueles que envolvem o setor de transportes. $\mathrm{O}$ estudo da literatura e a decantação, nessa, das habilidades para as PPPs exigem igualmente uma técnica apurada. Poucos são ainda os documentos que já listam de forma sistemática, com base em uma pesquisa própria, as referidas habilidades. A maior parte da literatura especializada foi investigada usando-se diversos filtros. Desse modo, as referidas habilidades podem aparecer, implicitamente, quando a literatura menciona atitudes/capacidades/competências, quando discorre sobre as experiências concretas; quando tece críticas e aponta as limitações das parcerias; ou ainda quando analisa as experiências fracassadas e as respectivas causas do insucesso. As habilidades têm nos FCS sua referência, e foram organizadas utilizando-se o princípio da arborescência, e complementadas pela análise de cluster. A partir daí, para agrupá-los, foi utilizado o método de otimização de Tocher, adotando-se a distância euclidiana média como medida de dissimilaridade. E desses resultados, nove grupos de habilidades foram criados: (i) Gerenciamento; (ii) Técnica; (iii) Organizacional; (iv) Psicológicas; (v) Educacional e Vocacional; (vi) Solução de Problemas; (vi) Negociação; (vii) Interpessoal; (viii) Pensamento e; (ix) Interpessoal.

Logo após este procedimento, com os grupos organizados e seus respectivos subcomponentes, estes foram julgados por juízes (especialistas), para fins de confirmação, mediante uma ponderação de itens (habilidades). Para isto, foi utilizado um formulário, com escalas, baseadas no método LJC. Foram consultados especialistas envolvidos diretamente com a área de recursos humanos e gestão de pessoas, e outros envolvidos diretamente com a oferta e demanda de profissionais (empresas e órgãos públicos) relacionados com o objeto de aplicação, ou experiências similares. Há predominância pelas habilidades interpessoais, solução de problemas, educacional vocacional e gerenciamento, como as mais importantes para os projetos de PPPs.

Atitudes: As atitudes foram identificadas à luz da literatura especializada e confirmadas junto aos especialistas (psicólogos, gestores de recursos humanos, ANTT, ARTESP, BID, BNDES, CONCEPA, ECONORTE, ECOSUL, e TCU), e organizadas conforme os seguintes grupos: cognitivos, afetivos e comportamentais. 
Figura 6: Priorização de Atitudes - Visão dos Especialistas

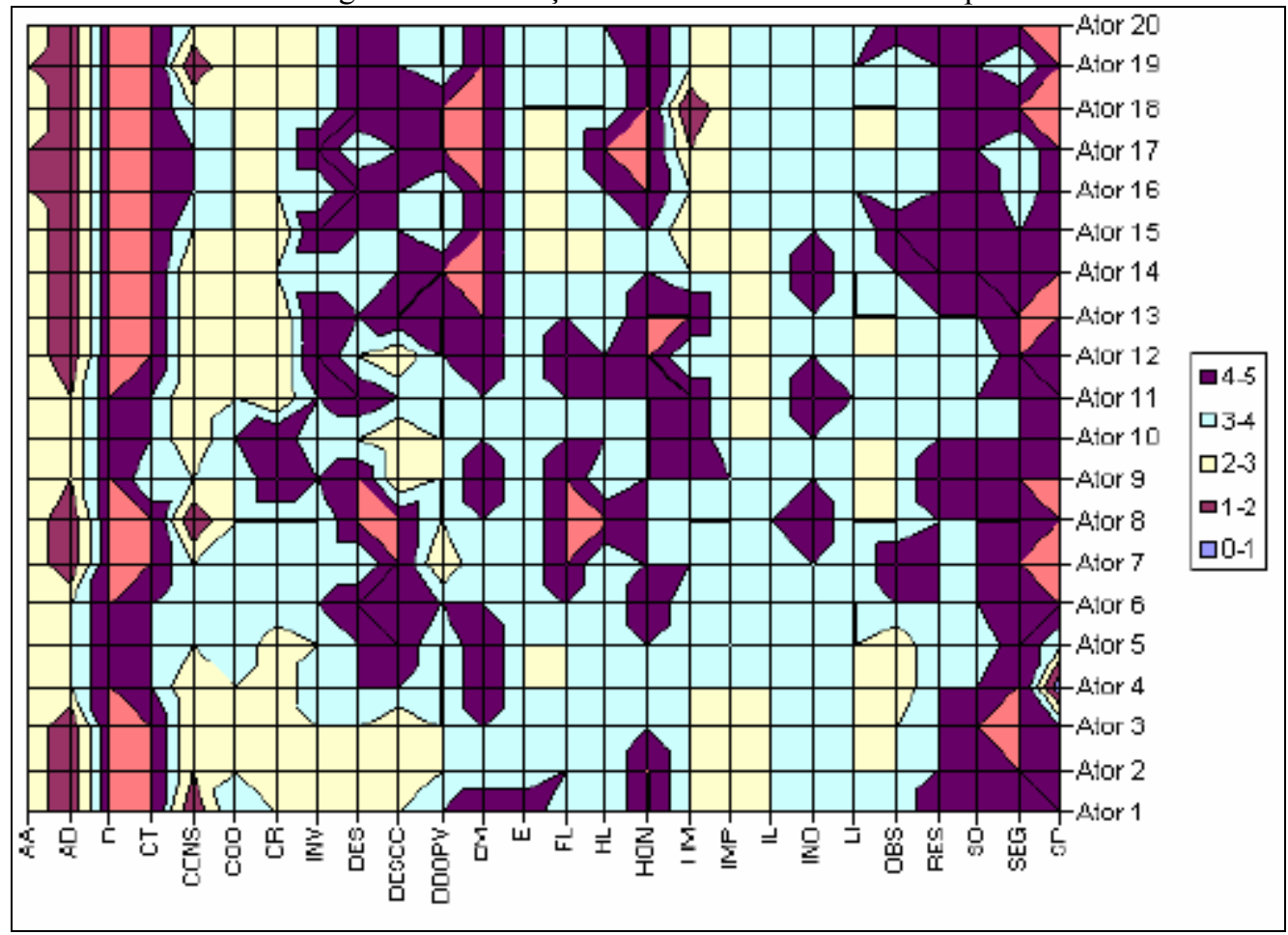

Fonte: Autoria própria

As atitudes foram priorizadas utilizando-se o método LJC. Uma vez identificadas as atitudes: auto-afirmativo (AA); autoritário-dominador (AD); (CT) comprometer-se-cumpridor de tarefas; (CONS) conservador; (COO) cooperar; (CR) criticar; (DE)desafiar-empreender; (DC) descontentamento construtivo; (DDOPV) determinado-dinâmico-ousado-proativo-versátil; (EM) entusiasta-motivado; (E) ético; (FL) flexível; (HL) holístico-visão sistêmica; (HON) honestoíntegro; (HM) humilde; (IM) imparcial; (IL) impor limites; (INO) inovar; investigar-examinarpesquisar- curioso; (LI) liderar; (OB) observador; (RESP) respeitoso; (R) responsável; (SO) saber ouvir; (S) seguro; e (SP) superar problemas-fracassos, essas foram priorizadas por especialistas, por meio de uma matriz de julgamento (formulário), onde os juízes atribuíram pesos, por importância (1 a 5). Utilizou-se o método LJC.

Em seguida, essas atitudes foram agrupadas (cluster) utilizando o método de otimização de Tocher, adotando-se a distância euclidiana média como medida de dissimilaridade. E atendendo ao princípio da arborescência, por afinidade. três grupos foram criados, segundo o método de otimização de Tocher: Grupo 1: Atitudes Afetivas; Grupo 2: Atitudes Cognitivas; Grupo 3: Atitudes Comportamentais. Na perspectiva dos pressupostos de um projeto de PPPs, as atitudes predominantes, priorizadas por importância, são: (CT) comprometer-se-cumpridor de tarefas; (DE)desafiar-empreender; (DDOPV) determinado-dinâmico-ousado-proativoversátil; (EM) entusiasta-motivado; (E) ético; (FL) flexível; (HL) holístico-visão sistêmica; (HON) honestoíntegro; (HM) humilde; (IM) imparcial; (IL) impor limites; (INO) inovar; (R) responsável; (SO) 
saber ouvir; (S) seguro; e (SP) superar problemas e fracassos. A seguir determinam-se os graus de avaliação de competências para verificar a convergência das interações entre as competências.

Fase 4: Determinação do Grau de Avaliação de Competências: A modelagem elaborada (Figura 7) para determinar os graus de avaliação de competências segue a analogia de Cury em 1999, utiliza a tecnologia neurofuzzy, e consiste em duas etapas: 1) determinação das competências desejadas na gestão de um projeto de PPPs, denominadas de Grau de Avaliação de Competências Desejadas - GACD; e 2) determinação das Competências Reais que os gestores possuem, denominadas de Grau de Avaliação de Competências Real - GACR. As competências desejadas são aquelas competências mínimas e necessárias à consecução das atividades e ações desenvolvidas nas AIs do projeto de PPPs: Política, Econômica e Financeira, Técnica e Mercadológica. Competências reais são aquelas que o gestor de PPPs possui, verificadas no momento que antecede a implementação do projeto de PPPs. Os resultados produzidos permitem verificar a discrepância entre as competências reais e desejadas. Recomenda-se um equilíbrio entre esses GAC. Porém, é uma oportunidade para então, lançar mão de estratégias que permitem aprimorar as competências reais no alcance das competências desejadas. A determinação dos GACD e GACD foi por meio da tecnologia neurofuzzy, que tenta reproduzir a classificação em tomada de decisão, que resulta na avaliação de desempenho das competências na gestão dos projetos de PPPs, na perspectiva dos projetos de PPPs/Concessões, para o setor de transporte rodoviário. O roteiro para a construção da presente modelagem que explora o potencial das redes neurofuzzy consiste nas seguintes etapas: (i) definição das variáveis de entradas; (ii) definição do sistema de inferência; e (iii) definição das variáveis de saídas. 
Figura 7: Modelagem neurofuzzy para determinar o GACD

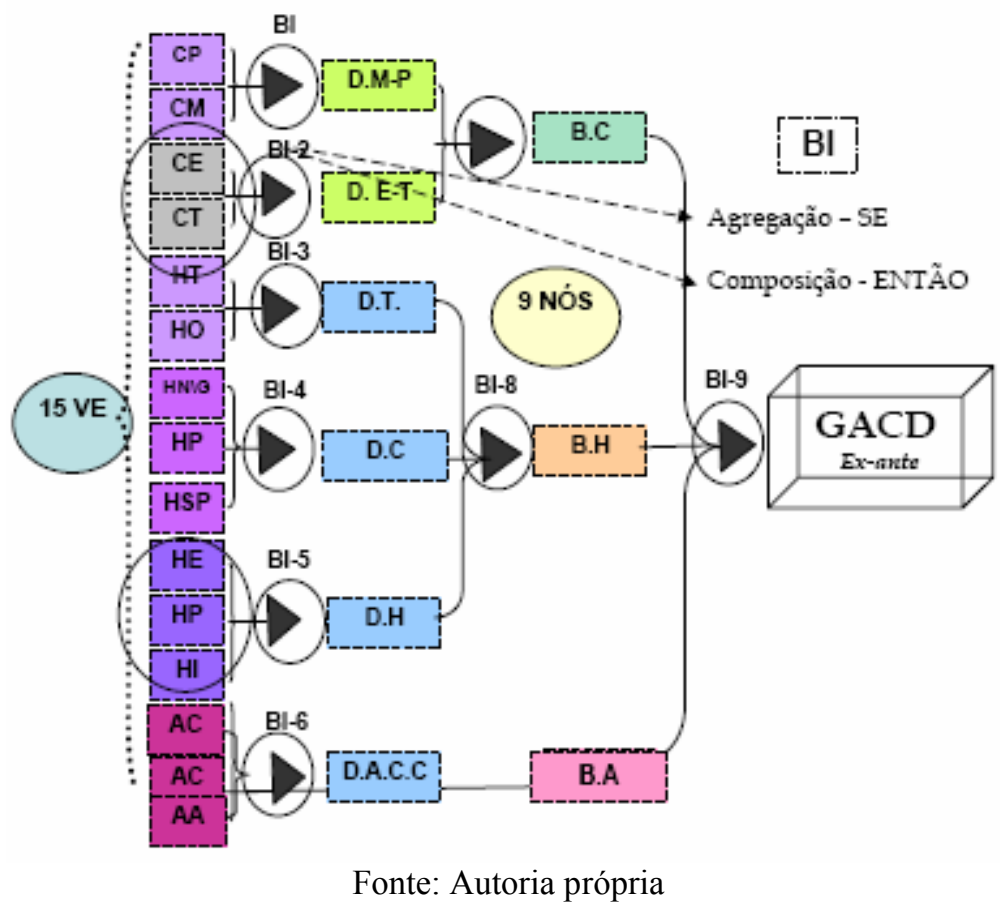

A determinação das variáveis de entradas (VE) do modelo foi a partir da média das competências levantadas na fase 3: conhecimentos, habilidades e atitudes, identicadas à luz da literatura e confirmadas junto a especialistas, na fase anterior.

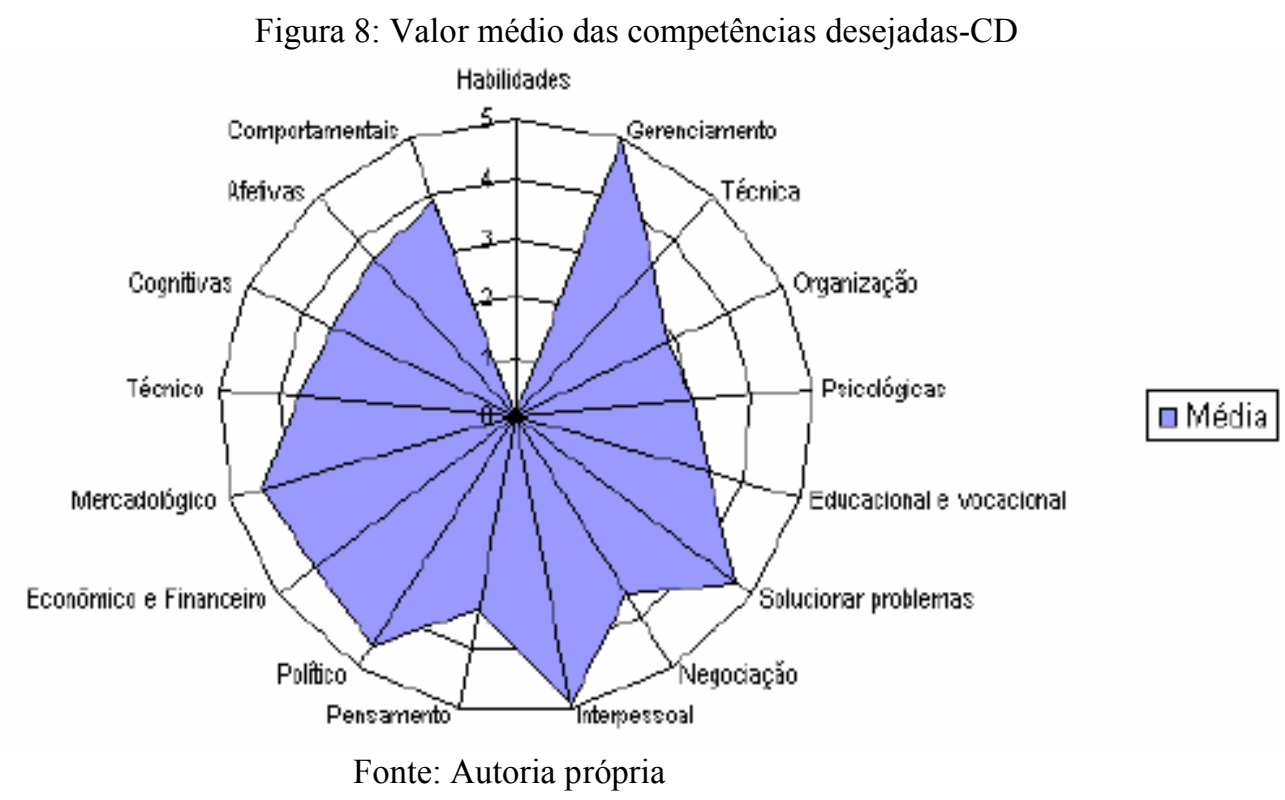

Essas VE, de natureza qualitativa, foram convertidas em variáveis lingüísticas, (GdC), com seus respectivos graus de certeza (GdC), na percepção dos especialistas. Esses GdC são subjetivos e baseados fundamentalmente na experiência e conhecimento dos especialistas. Em seguida, entra-se no sistema de inferência da rede neurofuzzy, arquitetado hierarquicamente, que utiliza bases de regras SE-ENTÃO, proporcionando, assim, um fator de evidência na opinião dos especialistas, por meio de uma variável lingüística final, que, por um processo de defuzificação lingüística, indica o 
GACD na gestão de projetos de parcerias público-privadas. A Figura 8 evidencia o valor médio dos valores das competências identificadas na fase anterior que, nesta fase são consideradas VE.

Essa média dos valores dos conhecimentos, habilidades e atitudes resultante da fase anterior, sob a intervenção de juízes, segue uma escala de priorização ou classificação de 1 a 5, apoiado no método de Thurstone, LJC, e aqui, constitui as VE do sistema neurofuzzy. Com a fusão das VE habilidades de gerenciamento e negócios, permitiu formar $15 \mathrm{VE}$, as quais são transformadas em variáveis lingüísticas, com seus respectivos $\mathrm{GdC}$, com a intervenção de juízes opinando no processo: (ANTT, TCU, BID, CONCEPA, ECOSUL, ECONORTE, ARTESP, Empresas de Recursos Humanos, Psicólogos). Em seguida, são definidas as variáveis intermediárias (VI).

\begin{tabular}{lccc}
\multicolumn{4}{c}{ Quadro 1: Variáveis intermediárias (VI) } \\
\hline \multicolumn{3}{c}{ Descrição } & Termos Lingüísticos \\
Desempenho Técnico & Baixo & Médio & Alto \\
Desempenho Humano & Baixo & Médio & Alto \\
Desempenho Conceitual & Baixo & Médio & Alto \\
Desempenho Mercado Político & Baixo & Médio & Alto \\
Desempenho Economico e Financeiro\Técnica & Baixo & Médio & Alto \\
DesempenhoAfetivo-Cognitivo-Comportamental & Baixa & Média & Alta \\
Beneficio Habilidades & Baixo & Média & Alta \\
Beneficio Conhecimentos & Baixo & Médio & Alto \\
Beneficio Atitudes & Baixo & Médio & Alto \\
\hline
\end{tabular}

Fonte: Autoria própria

Após a conversão de todas as VE em suas correspondentes variáveis lingüísticas, com seus respectivos $\mathrm{GdC}$, os blocos de inferência fuzzy (BI), compostos por base de regras SE-ENTÃO, são operados com base nos operadores MIN-MAX, obtendo-se um valor lingüístico para cada variável intermediária e para variável de saída do modelo, com os termos lingüísticos definidos pelos juízes, anteriormente. A partir das VE, geram-se a base de regras. Cada regra possui um fator de ponderação individual, denominado de fator de certeza (FdC), compreendido entre 0 e 1 , que indica o grau de importância de cada regra na base de regras fuzzy. E a inferência fuzzy ocorre a partir da base de regras, gerando o vetor lingüístico da VS, obtido por meio das etapas de agregação e composição. O uso do conjunto fuzzy para defuzzificação permite obter o GACD. O vetor lingüístico do GACD passa pelo processo de defuzificação para ser transformado em um número real, entre 0 e 1, mínimo e máximo respectivamente, procedimento este realizado utilizando a técnica Centro dos Máximos (CM), no tratamento da variável de saída final, expresso de forma numérica. $\mathrm{O}$ valor do GACD numérico numa escala de 0 a 1 corresponde a 0,6428 , resultante da média aritmética dos valores produzidos na defuzificação de cada um dos juízes simulados. Este valor corresponde a um valor médio para o GACD.

Uma vez determinado o GACD, em seguida determina-se o GACR dos gestores de PPPs utilizando a modelagem neurofuzzy com procedimentos similares aos aplicados na determinação do GACD. Porém aqui as VE são determinadas conforme cada dimensão: conhecimentos, habilidades 
e atitudes, e consistiu em: Primeiramente, a identificação dos conhecimentos dos gestores de PPPs por meio de testes/provas, com itens ou questões abertas. De posse desses resultados avaliados, procede-se um ajuste numa escala de 1 a 5, em que 1 representa o valor mínimo de importância ou de domínio no conhecimento e 5 representa o valor máximo. Em seguida calcula-se a média dos resultados produzidos. Logo após, procede-se ao levantamento das habilidades dos gestores com apoio da escala do tipo Likert, individualmente. Em seguida, determinam-se as atitudes dos gestores com o apoio do método LJC. Os valores resultantes desta análise preliminar, média das dimensões (Figura 9), são as VE para a modelagem neurofuzzy, convergindo para o GACR.

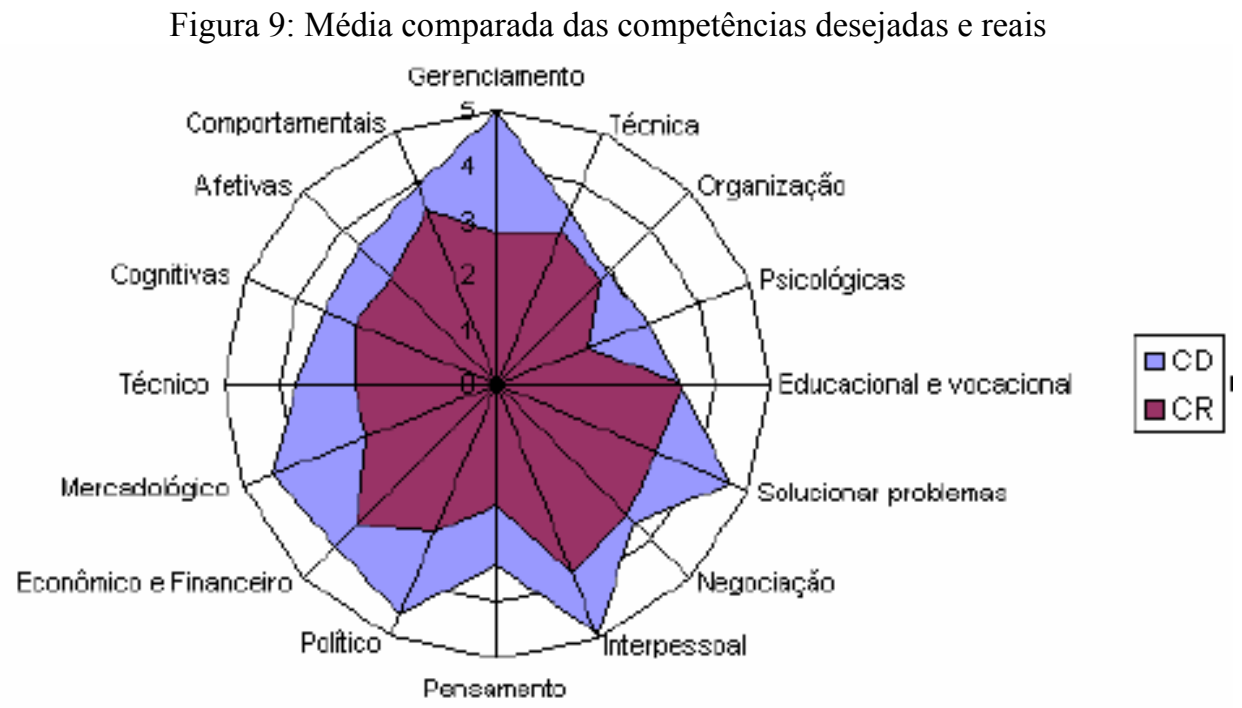

Fonte: Autoria própria

Estabelecendo-se uma análise comparada da evolução dos GACD e GACR, os resultados são evidenciados na Figura 9.

A interação entre as competências reais produz o GACR do gestor, numa escala de 1 a 10 , os quais são os valores das VE, de natureza qualitativa, do sistema neurofuzzy. O resultado dessa interação entre as competências reais é evidenciado na Figura 10. 
Figura 10: Modelagem Neurofuzzy para o Grau de Avaliação de Competências Reais

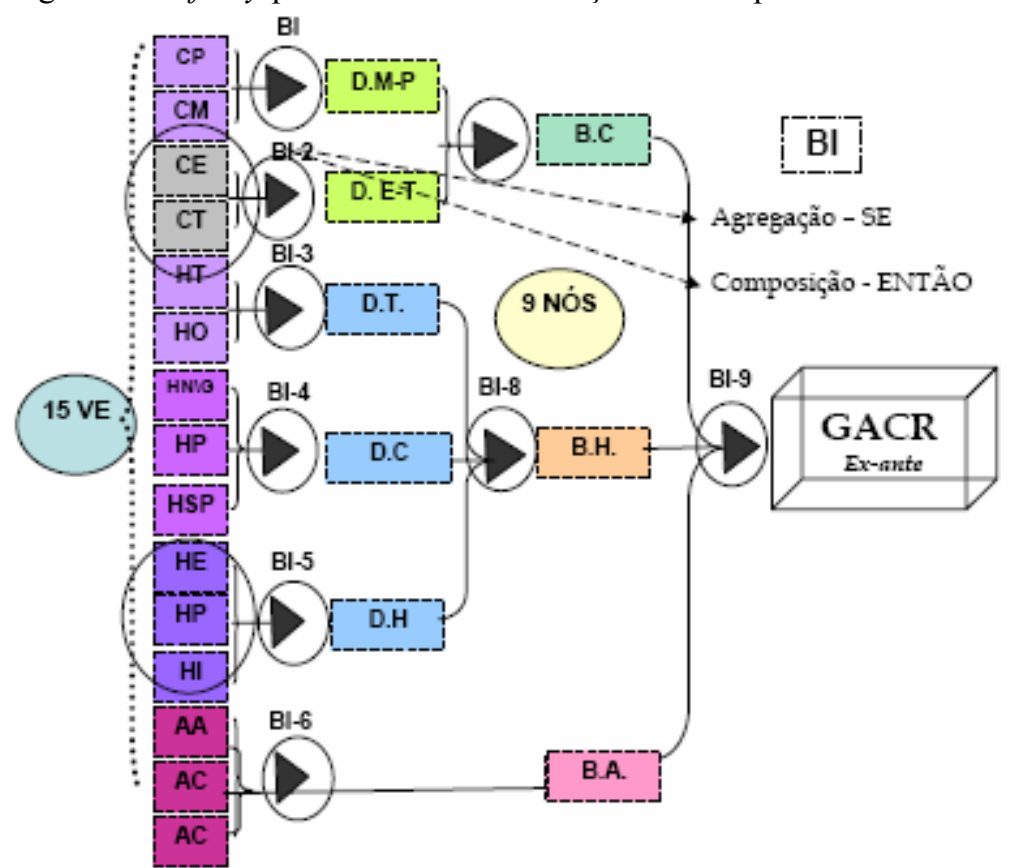

Fonte: Autoria própria

O GACR produzido corresponde a 0,4246. Esse GACR reflete a interação entre as competências que os gestores possuem e que podem ser aprimoradas vislumbrando o alcance das competências desejadas, traduzidas pelo GACD, o que requer estratégias de capacitação especialmente desenhadas para esse aperfeiçoamento. No campo metodológico, hão de procurar abordagens mais amplas e sistêmicas, capazes de reunir os mais diversos métodos e modelos inovadores que tratam das PPPs. A conclusão que se pode tirar dos aspectos positivos e negativos do desenvolvimento desta modelagem aplicado às PPPs é oportunizar a todos àqueles envolvidos direta ou indiretamente com projetos infra-estruturais sobretudo no setor de transportes. Concretamente, a política de PPPs deve se pautar ativamente pela democratização das oportunidades, mesmo considerando as limitações.

\section{Palavras Finais: Lições aprendidas}

Diversos fatores podem incrementar o interesse e popularidade das PPPs. A eficiência nos serviços e alocação dos recursos, certamente tem contribuído para as potencialidades deste instrumento. Sendo assim, evidencia-se as PPPs como um instrumento de retomada do desenvolvimento nos planos infra-estruturais, na medida em que reativaria os esforços, apontando melhoria da qualidade das políticas públicas nas PPPs, sobretudo no tocante a forma de se fazer planejamento. Crê-se ainda que essa reativação só é possível desde que democratize a feição e a gestão de tais projetos.

É importante lembrar que a modalidade de PPPs não é uma panacéia para resolver qualquer problema infra-estrutural, mas acredita-se que, quando bem concebido, organizado e gerido, pode 
conduzir a resultados bastante positivos e com grande impacto. Seja como for, as tentativas fracassadas de PPPs cedem espaços para reforçar a importância de seu papel dando um salto para modelos mais inovadores e livres de riscos de errar. Não está substituindo um Poder de Polícia de controle das atividades e ações, e nem desprivilegiando o que já deu certo, mas fomentando o pragmatismo no implemento das PPPs com responsabilidade. Aliás, o processo de formação de um modelo inovador de PPPs inaugura uma nova forma de relacionamento entre o Poder Público e a Iniciativa Privada: um relacionamento em que a sociedade não se encontra mais capitaneada tãosomente pelo Poder Público.

O resto da discussão são procedimentos metodológicos, e neste campo, a técnica impôs um padrão suficientemente robusto e lógico-científico planejado. O estoque de sofisticação dos procedimentos metodológicos privilegiou diversas dimensões necessárias para compreender e interpretar a lógica subjacente às PPPs.

Esta proposta visa, antes de tudo, que se iluminem questões ainda não exploradas neste objeto tão-complexo. Evidentemente, não pretende ser uma camisa de força metodológica, mas que venha prestar uma contribuição, mesmo que por caminhos mais livres. Além disso, esse suporte metodológico não tem a pretensão de ser completo, mas sim, de ser gerador de elementos do conhecimento que são estratégicos para o desenvolvimento de projetos de PPPs, o que torna o espectro de decisão mais inteligente, disponibilizando elementos essenciais para a elaboração de projetos como esses.

Ressalta-se ainda a grande contribuição da aplicação desse modelo fundamentada na possibilidade de tratamento da subjetividade considerada no planejamento de projetos de parcerias público-privadas.

A tecnologia neurofuzzy foi estruturada de forma a convergir as diversas dimensões (conhecimentos, habilidades e atitudes) das competências em um único valor denominado GAC, que reflete o quanto de competências é desejado de cada gestor na perspectiva do gerenciamento de projetos de parcerias público-privadas. E o resultado desta aplicação indicou o quanto a técnica é adequada para a estruturação do modelo proposto, principalmente, quanto à baixa complexidade e à flexibilidade. Além disso, essa ferramenta possibilita a consideração de variáveis subjetivas que correspondem às dimensões (conhecimentos, habilidades e atitudes) desejadas em decisões de projetos de parcerias público-privadas.

Reconhece-se ainda a importância das metodologias especialmente desenhadas no reconhecimento da subjetividade dos decisores, a influência dos fatores subjetivos sobre a percepção e entendimento das informações disponíveis ao decisor advindas do contexto decisório. Evidencia-se assim, a relevância dos métodos multicriteriais, Compromise Programming, Electre e Promethee, que mostraram-se eficientes ao determinar o desempenho das áreas de informações em 
relação aos FCS. A escala de Thurstone, que considera a dinâmica temporal das manifestações de probabilidade de preferências dos juízes, demonstrada em diversas etapas desta aplicação. A tecnologia neurofuzzy, fortemente apoiada na opinião dos especialistas, apropriada a esta aplicação por envolver um elevado número de variáveis e pelo seu caráter flexível, favorecendo o processo de classificação das competências para as PPPs.

Seja como for, a política de PPPs haverá de estar ancorada em um planejamento instrumentalizado na perspectiva dos recursos humanos, e esses com capacidade dinâmica e autônoma para formar suas respectivas capacidades. A qualificação dos recursos humanos deve ser balizada como uma prioridade do momento. E no contexto desses esforços sistêmicos é fundamental desenvolver as competências individuais requeridas e buscar o máximo uso dos recursos, tanto no campo da tecnologia como dos recursos humanos.

Conforme já salientado, os projetos de PPPs são complexos e arriscados, e portanto, requerem dos gestores competências mínimas e críticas à elaboração e implementação desta categoria de projetos. Nesta perspectiva, a contribuição deste artigo ruma oportunizar um instrumento para aperfeiçoar a política de gestão das parcerias público-privadas ao considerar um tema tão relevante como as competências desejadas na gestão das PPPs.

Por se tratar de uma temática tão relevante no contexto histórico atual de nosso País, recomenda-se que este estudo, dada a factibilidade demonstrada do método, seja continuado e atualizado de forma permanente e recorrente, permitindo o acompanhamento das mudanças ocorridas no contexto que se insere os projetos de PPPs.

\begin{abstract}
This paper intends to contribute to the planning guidelines in the field of PPPs. Thus, it develops a multi-model reference proposal supported by the definition of a highly complex spectrum of competence that considers a sequence of systematic procedures in the following phases: (i) Determining the information needs in two stages: (a) identification of the critical success factors (CSF), and (b) identification of the information areas; (ii) Determination of competences; and (iii) Determination of the degree of competence evaluation. The data collection was conducted by means of a semi-structured form, the scalar type in a trial matrix, to which experts ascribed their assessments. Several support instruments were used in the modeling elaboration in order to reduce subjectivity in the results: psychometric scales - Thurstone's Law of Comparative Judgment (LCJ), multi-criteria Compromise Programming, Electre III, and Promethee II; Multivariate Analysis; Artificial Neural Networking (ANN); Neuro-fuzzy networks. The results produced are satisfactory, validating the proposed procedure for PPPs.
\end{abstract}

Key-words: public-private partnerships (ppps); competence; multi-model reference.

\title{
Referências
}

BENNETT E, GROHMANN P, GENTRY B: Public-Private Partnerships for the Urban Environment Options and Issues. PPPUE Working Paper Series, (1). New York: UNDP e Yale University, 1999. 
BUKOWITZ, W. R.; WILliAMS, R. L. Manual de Gestão do Conhecimento: ferramentas e técnicas que criam valor para a empresa. Porto Alegre: Bookman, 2002.

BUCHANAN, E. A. An overview of information ethics issues in a world-wide context. Ethics and Information Technology, 1(3), 193-201, 1999.

\section{cross ${ }^{\text {ref }}$}

CELIS, F. C. Identificação e Priorização das Necessidades de Informação das Empresas de Transporte Urbano de Passageiros para a Montagem de um Sistema de Inteligência Estratégica. Dissertação de Mestrado, Universidade de Brasília, Brasília, PR, Brasil, 2000.

CURY, M. V. Q. Modelo Heurístico Neurofuzzy para Avaliação Humanística de Projetos de Transporte Urbano. Tese de Doutorado, Universidade Federal do Rio de Janeiro, Rio de Janeiro, RJ, Brasil, 1999.

DAVENPORT, T.; PRUSAK, L. Working Knowledge: How Organizations Manage What They Know, Harvard Business School Press. Rio de Janeiro: Qualitymark, 1998.

DAVENPORT, T. H. Ecologia da informação (3a ed.) (B. Siqueira, Trad.). São Paulo: Futura, 2001.

INGERSON, A. E. Public-private partnerships. Cambridge, Maas.: Harvard College. Recuperado em 18 julho, 2009 , de http://www.icls.harvard.edu/ppp/contents.html, 2000.

LAUDON, K. C., LAUDON, J. P. Management information systems: new aproaches to organisation and technology. Upper Saddle River, NJ: Prentice-Hall, 1998.

LAUDON, K. C.; LAUDON, J. P. Gerenciamento de sistemas de informação. 3. Ed. Rio de Janeiro: LTC, 2001.

LITTO, F.M. ; FORMIGA, M. Educação a Distância: o estado da arte. São Paulo: Pearson Education do Brasil, 2008.

MORESI, E. A. D. Gestão da informação e do conhecimento. Brasília: Editora UnB. Nonaka I. (1994). A dynamic theory of organizational knowledge creation. Organization Science; 5(1), 14-37, 2001.

NONAKA, I. TAKEUCHI, H. The knowledge-creating company: how Japanese companies create the dynamics of innovation. New York, NY: Oxford University Press, 1995.

O’BRIEN, J. A. Sistemas de informação e as decisões gerenciais na era da internet. São Paulo: Saraiva, $2001 .$.

OFFICE OF GOVERNMENT COMMERCE: Leadership guide. OGC Best Practice.Gateway Review. London: Office of Government Commerce, 2001.

PARTNERSHIPS VICTORIA. Practitioners' Guide. Melbourne: Department of Treasury and Finance of the State of Victoria, 2001.

PADECO CO. LTD. Highway Planning Inc., Value Management Institute Inc. (1999): Seminaron Asian Toll Road Development in an Era of Financial Crisis Tokyo International Forum: March 9 11, Proceedings of the Seminar: Appendices A through F. . Tokyo:The World Bank, Ministry of Construction of Japan, 1999.

PROBST, G.; STEFFEN, R.; Romhardt, K. Gestão do conhecimento: os elementos construtivos do sucesso. Porto Alegre - RS: Bookman, 2002.

PROVINCE OF NOVA SCOTIA: Municipal Services - Strategic Public-Private Partnering: A Guide for Nova Scotia Municipalities. Background: What is a Public Private Partnership?. Halifax Province of Nova Scotia, 2003.

QUEEnsland Government: Draft Public Private Partnerships Policy Summary. Sydney: Property Council of Australia. Recuperado em 14 de junho, 2008, de http://www.propertyoz.com.au., 2001.

STAIR, R., REYNOLDS, G.. Principles of Information Systems. Cambridge: ITP, 2002.

THIEL, E.E. Proposta de modelo de implantação de um projeto de gestão do conhecimento com base em processos organizacionais. Dissertação de Mestrado, Universidade Federal de Santa Catarina, Florianópolis, SC, Brasil, 2002. 
Dados dos autores:

\section{Edson Walmir Cazarini}

Universidade de São Paulo

Engenharia de Produção

Professor

Trabalhador São Carlense, 400 - São Carlos, São Paulo - CEP: 13566-590

1633738238

cazarini@sc.usp.br

\section{Selma Regina Martins Oliveira}

Universidade de São Paulo

Engenharia de Produção

Professor

Trabalhador São Carlense, 400 - São Carlos, São Paulo - CEP: 13566-590

3432161940

selmaregina@webmail.uft.edu.br 